\title{
FRANCISCO MARTÍNEZ DE LA ROSA Y LAS CONFLICTIVAS RELACIONES IGLESIA-ESTADO EN ESPAÑA (1834-1835)
}

\author{
POR \\ MARÍA JosÉ VILAR GARCÍA* \\ Universidad de Murcia \\ mavi@um.es
}

\section{RESUMEN}

Aportación y análisis de una correspondencia inédita de Francisco Martínez de la Rosa a su paso por la presidencia del Gobierno español en el bienio 1834-1835, mantenida con Luigi Amat di San Filippo, nuncio en funciones en España, y conservada en el Archivo Secreto Vaticano. Se trata de tres cartas con formato de despacho oficial, pero por sus contenidos más bien misivas confidenciales, en las que el gobernante español se afana, aunque sin éxito, en lograr el reconocimiento por Roma de Isabel II y de su régimen liberal. Especial atención a la urgente necesidad de cubrir las numerosas sedes episcopales vacantes en España.

PalABRAS ClAVE: $\quad$ Francisco Martínez de la Rosa; Luigi Amat di San Filippo; Isabel II; papa Gregorio XVI; Tommaso Bernetti; Santa Sede; Roma; España; relaciones hispano-pontificias; diócesis vacantes; 1834-1835.

\section{FRANCISCO MARTÍNEZ DE LA ROSA AND CHURCH-STATE CONTROVERSIAL RELATION IN SPAIN (1834-1835)}

\begin{abstract}
This study aims to provide and analyze Francisco Martínez de la Rosa's unpublished correspondence during his term as President of the Spanish Government in the 1834-1835 biennium, maintained with Amat di San Filippo Luigi, nuncio in Spain, and kept in the Vatican Secret Archives. Such correspondence consists of three letters with official mail format, although they could be considered rather confidential for their content. In these documents, the Spanish government strives, albeit unsuccessfully, to achieve recognition by Rome of Elizabeth II of Spain and his liberal regime. And last but not least, in this paper, it is also noteworthy to highlight the urgent need to fill the many vacant Dioceses in Spain.
\end{abstract}

KEY WORDS: Francisco Martínez de la Rosa; Luigi Amat di San Filippo; Elizabeth II of Spain; Pope Gregory XVI; Tommaso Bernetti; Holy See; Rome; Spain; spanish pontifical relationships; projected vacant dioceses; 1834-1835.

Recibido/Received 29-10-2013

Aceptado/Accepted 10-11-2015

\begin{tabular}{ll}
\hline \multicolumn{1}{c}{ SIGLAS } & \\
AMAE & : Archivo del Ministerio de Asuntos Exteriores (Madrid) \\
ANM & : Archivio Nunziatura di Madrid (Sec. del ASV, Roma) \\
AA.EE.SS. & : Archivio della Sacra Congregazione degli Affari \\
& Eclesiastici Straordinari (Sec. del ASV, Roma) \\
ASV & : Archivio Segreto Vaticano (Roma) \\
BAE & : Biblioteca de Autores Españoles (colección) \\
BAC & : Biblioteca de Autores Cristianos (editorial) \\
coord & : Coordinador \\
CEC & : Centro de Estudios Constitucionales (Madrid) \\
CEPC & $:$ Centro de Estudios Políticos y Constitucionales \\
& (Madrid) \\
CSIC & $:$ Consejo Superior de Investigaciones Científicas \\
& (Madrid) \\
Ed. & $:$ Editorial \\
ed & $:$ Editor /edición \\
id. & $:$ El mismo
\end{tabular}

$\begin{array}{ll}\text { infra } & \text { : Más abajo } \\ \text { IEF } & : \text { Instituto de Estudios Fiscales (Madrid) } \\ \text { IEP } & \text { : Instituto de Estudios Políticos (Madrid) } \\ \text { Op. cit. } & \text { : Obra citada } \\ \text { p./pp. } & \text { : Página / páginas } \\ \text { supra } & \text { : Más arriba } \\ \text { Sec. } & \text { : Sección } \\ \text { SS } & \text { : Segretaria di Stato } \\ \text { t } & \text { : Tomo } \\ \text { Univ } & \text { : Universidad }\end{array}$

* Esta investigación ha sido realizada en el marco de los Proyectos de investigación: Hispanofilia III: la influencia ibérica en su contexto político, siglos XVI-XX, Código HAR2014-52414-C2-1-P, Ministerio de Economía y Competitividad y Columnaria I. Comprender las dinámicas de los Mundos Ibéricos, exp.19247/PI/14 de la Fundación Séneca, Agencia de Ciencia y Tecnología Región de Murcia. 


\section{INTRODUCCIÓN}

En el Archivo Secreto Vaticano, Sec. Nunciatura de Madrid, leg. 293 (Nunciaturas de F. Tiberi y L. Amat) se conservan tres misivas del entonces jefe del Gobierno español Francisco Martínez de la Rosa, fechadas en 12 de septiembre y 26 de octubre de 1834, y en 11 de enero de 1835, dirigidas a Luigi Amat di San Filippo e Sorso, arzobispo de Nicea y a la sazón en funciones de nuncio de la Santa Sede en España. Correspondencia no recogida en el básico y amplio repertorio diplomático editado y anotado por Vicente Cárcel Ortí sobre Amat durante su estancia en Madrid entre 1833 y 1840 (fundamentalmente, además de otra documentación complementaria, los despachos cruzados entre éste y el cardenal Tommaso Bernetti, pontificio secretario de Estado), ${ }^{1}$ como tampoco en las restantes recopilaciones documentales existentes relacionadas directa o indirectamente con Martínez o Amat. $^{2}$

Es de señalar que las tres cartas de referencia, aunque con formato de despachos oficiales, en razón de la intencionalidad del autor, y sus contenidos, son más bien misivas confidenciales. Se centran en la fundamental cuestión del no reconocimiento de Isabel II por la Santa Sede durante los años iniciales de su reinado, circunstancia que imposibilitó la provisión por Roma de numerosas sedes episcopales vacantes en España, con los consiguientes efectos perturbadores en el funcionamiento de esas diócesis, cuestiones ambas que Martínez de la Rosa se esforzó en resolver a su paso por el Gobierno, pero sin éxito. Por lo demás los tres documentos aportados contienen interesante y novedosa información adicional sobre otros aspectos de las relaciones hispano-pontificias y la realidad eclesial española de la época, como también sobre el conflicto dinástico español y subsiguiente contienda civil de siete años (1a guerra carlista, 1833-1840), respecto a los datos aportados por las fuentes documentales conocidas y consultadas hasta el momento. De ahí el manifiesto interés de la documentación aquí presentada.

\section{CONTEXTO HISTÓRICO}

La crisis dinástica en España, llamada a derivar en cruenta y tenaz guerra civil, comienza a atisbarse con el nacimiento el 10 de octubre de 1830 de Isabel Luisa (futura Isabel II), habida del cuarto enlace matrimonial de Fernando VII con su sobrina María Cristina de Borbón-Dos Sicilias, dado que el monarca no había tenido descendencia en sus tres matrimonios anteriores. Con la promulgación por Fernando de la Pragmática Sanción restableciendo el orden sucesorio tradicional español no excluyente para las mujeres, y que había sido abolido por Felipe $V$ al implantar la francesa Ley Sálica, la cuestión dinástica quedó formalmente planteada, dado que la princesa Isabel fue antepuesta en el orden sucesorio a su tío el infante Carlos Ma. Isidro, el mayor de los hermanos varones del monarca, y hasta el momento su incuestionable heredero.

1 Cárcel Ortí, V. (ed.) 1982. Correspondencia diplomática de los Nuncios en España. Nunciatura de Amat. 1833-1840. Pamplona: EUNSA.

2 Referencias en notas infra.
El fallecimiento de Fernando en 29 de septiembre de 1833, seguido de la entronización de su hija Isabel II (2 octubre), y el rechazo por don Carlos de tal acuerdo al autoproclamarse monarca con el apoyo de un amplio sector social apegado a tradiciones ancestrales e históricas, determinó una prolongada y asoladora guerra civil, cerrada en 1840 con el triunfo de la opción isabelina. Ahora bien, el derrotado carlismo continuó siendo considerado por sus partidarios como alternativa legítima, prolongándose por tanto la cuestión dinástica casi indefinidamente, hasta bien entrado el siglo xx.

Como quiera que la opción carlista tuvo un gran seguimiento entre el clero español, la consiguiente reacción anticlerical en ambientes liberales y pro-liberales condicionaron negativamente, y por largo tiempo, las relaciones entre España y la Santa Sede. Situación esa radicalizada por el creciente incremento de una abierta militancia anti-isabelina en las filas eclesiales en el curso de la guerra civil y por las simpatías pro-carlistas más o menos encubiertas en amplios sectores del restante clero, actitud compartida por el propio pontífice Gregorio XVI, ${ }^{3}$ quien muy influenciado además por Austria, con Prusia y Rusia principal adalid internacional de la causa carlista, proclamó la neutralidad de la Santa Sede respecto a la cuestión dinástica española, acuerdo que obviamente benefició a don Carlos, ya autotitulado Carlos V. ${ }^{4}$

Por todo ello el nuncio Francesco Tiberi hubo de ser relevado, y su sucesor en Madrid, Luigi Amat, por el momento no recibió del Gobierno español el plácet o regium exequatur a su nombramiento, como tampoco pudieron acreditarse los representantes de España en Roma, de forma que las relaciones entre ambas partes de hecho quedaron rotas. Circunstancia esa aprovechada por los sucesivos gobiernos españoles, a partir del presidido por el liberal-moderado Francisco Martínez de la Rosa en el bienio 1834-1835, para sacar adelante su política secularizadora, radicalizada luego por sus sucesores hasta culminar con los decretos de

3 Gorricho Moreno, J. 1962. "El pretendiente Carlos V y el papa Gregorio XVI". Anthologica Annua 10: 731-741; Gorricho Moreno, J. 1983. "Algunos documentos vaticanos referentes al pretendiente Carlos V (1834-1842)". Anthologica Annua 11: 339-365; Cárcel Ortí, V. 1974. "Gregorio XVI y España". Archivum Historiae Pontificiae 12: 235-285.

4 El contexto internacional de las relaciones de España con la Santa Sede durante el conflictivo despegue del régimen isabelino (bienio 1834-1835) puede verse, entre otros, en Renouvin, P. 1982. Le XIX siécle. I: De 1815 a 1871. L'Europe des nationalités à l'eveil de nouveaux mondes, t. $\mathrm{V}$ de Histoire des Relations Internationales. Madrid: Aguilar -1aㅡ ed. francesa. París. 1954-; Pereira, J.C. 1983. Introducción al estudio de la política exterior de España (siglos XIX y $x x$ ). Madrid: Ed. Akal; López-Cordón Cerezo, Mạ.V. 1983: "La política exterior" en J.Ma. Jover (dir.), La era isabelina y el Sexenio democrático (1834-1874), t. XXXIV de Historia de España. Menéndez Pidal: 821899. Madrid: Espasa-Calpe; Jover, J.Ma. 1999. "Caracteres de la política exterior de España en el siglo XIX", en J.Mạ. Jover, España en la política internacional. Siglos XIX y XX: 111-172. Madrid: Marcial Pons -reimpresión de eds. precedentes-; Vilar, J.B. 1989. "Las relaciones internacionales de la España isabelina: precisiones conceptuales y anotaciones bibliográficas" en J.B. Vilar (ed.), Las Relaciones internacionales en la España contemporánea. Presentación de J.Mạ. Jover: 37-80. Murcia-Madrid: Univ. de Murcia-Univ. Complutense; Vilar, J.B. 2010. "España en la Europa de los nacionalismos: entre pequeña nación y potencia media (1834-1874)", en J.C. Pereira (coord.), La política exterior de España. De 1800 hasta hoy. Historia, condicionantes y escenarios. 535-554. Barcelona: Ariel. 
exclaustración general y desamortización promulgados por Juan Álvarez Mendizábal y Pascual Madoz en 1836 y $1854-56 .{ }^{5}$

Es de señalar que, al margen de las alegaciones legitimadoras invocadas por los liberales en pro de una reforma modernizadora de las anquilosadas estructuras eclesiales, reforma desde luego necesaria, el objetivo básico pretendido no era otro que allegar recursos para afrontar con éxito la contienda civil, con el argumento de que siendo evidente que el clero apoyaba muy mayoritariamente a don Carlos en su levantamiento armado, prolongando así los sufrimientos de la nación, debería coadyuvar a cubrir los gastos bélicos de la causa legítima. Acuerdo gubernativo ese secundado en la calle por una explosión popular de anticlericalismo más o menos manipulado por sociedades secretas de signo radical so pretexto de que la guerra se estaba perdiendo en parte por el fuerte apoyo eclesial humano y económico al carlismo (sucesos de julio de 1834 y meses siguientes). Actuaciones esas en Madrid y otras localidades con fuerte implantación liberal, dirigidas especialmente contra el clero regular o conventual, tachado por sus enemigos como manifiestamente reaccionario, además de socialmente inútil, disturbios que se tradujeron en asaltos, expolios e incendios de conventos, e incluso en el asesinato de numerosos religiosos so pretextos tan absurdos, y no probados, como el esgrimido por los amotinados madrileños al acusar a los frailes de haber envenenado las fuentes públicas y ser por ello responsables de la epidemia de cólera que desde un tiempo atrás se abatía sobre esa y otras localidades españolas. ${ }^{6}$

Tal fue el negro panorama que Francisco Martínez de la Rosa hubo de afrontar a su paso por la presidencia del Gobierno de la nación durante un denso y complejo mandato de año y medio. Entre 15 de enero de 1834, en que sustituyó al absolutista-reformista Francisco Zea Bermúdez, y 5 de junio de 1835, en que dio paso al liberal-progresista José Ma. Queipo de Llano y Ruiz de Saravia, conde de Toreno. ${ }^{7}$

Véanse, entre otros: Bécker, J. 1908. Relaciones diplomáticas entre España y la Santa Sede durante el siglo XIX. Madrid: Jaime Ratés; Castillo y Ayensa, J. del 1859. Historia crítica de las negociaciones con Roma desde la muerte de Fernando VII. Madrid: Tejado, vol. I (2 vols.); Cuenca Toribio, J.M. 1965. Don Pedro de Inguanzo y Rivero (1764-1836), último primado del Antiguo Régimen. Pamplona: Univ. de Navarra; Cuenca Toribio, J.M. 1971. La Iglesia española ante la Revolución liberal: 15-69 Madrid: Ed. Rialp; Cárcel Ortí, V. 1975. Política eclesial de los Gobiernos liberales españoles (1830-1840): 143-318 Pamplona: Univ. de Navarra; Andrés Gallego, J. y Pazos, Antón M. 1999. La Iglesia en la España contemporánea, I. 1800-1936: 51-93 Madrid: Ediciones Encuentro; Moliner Prada, A. 1998. "Anticlericalismo y revolución liberal (1833-1874)" en E. La Parra López y M. Suárez Cortina (eds.): El anticlericalismo español contemporáneo: 69-126. Madrid: Ed. Biblioteca Nueva; Revuelta González, M. 2010. La exclaustración, 2aㅡ ed., Madrid: Fundación Universitaria San Pablo CEU -1ạ ed.: Madrid, BAC, 1976-.

Jemolo, A.C. 1947. “I principii della guerra carlista e la Nunziatura di Madrid". Ressegna Storica del Risorgimento 34, I-II: 6-14; Izaguirre Irureta, F. 1958. "Las relaciones diplomáticas de la Santa Sede con el Gobierno español durante la primera guerra carlista". Universidad (Zaragoza) 35: 569-593; Cuenca Toribio, J.M. 1967: “La desarticulación de la Iglesia española del Antiguo Régimen (1833-1840)". Hispania Sacra (CSIC) 20; Revuelta González, M. 1992. "El estallido anticlerical de 1834". xx Siglos, a. 3, 11: 136-141.

Cuenca Toribio, J.M. y Miranda García, S. 1998. El poder y sus hombres. ¿Por quienes hemos sido gobernados los españoles? (17051998). Madrid: Ed. Actas, 26, 230, 262, 652, 653; Urquijo Goitia, J.R. 2001. Gobiernos y ministros españoles (1808-2000): 36-37 Madrid: CSIC.

\section{Martínez de La Rosa y SUS RELACIONES Con la SANTA SEDE}

Francisco Martínez de la Rosa Berdejo (Granada, 1787-Madrid, 1862), perteneciente a una acomodada familia de la burguesía agraria granadina emparentada con acaudalados mercaderes gaditanos y formado en la Universidad de Granada, de ideología liberal-progresista en su juventud y liberal-conservadora en la madurez, fue pronto un brillante e innovador literato de primera fila, sobre todo en la línea de la dramaturgia romántica, en la que dejó extensa y perdurable obra. ${ }^{8}$ Todo ello sin perjuicio de figurar también en un primer plano de la política activa, esforzándose desde las filas del Partido Moderado ${ }^{9}$ por sacar adelante una apertura gradual, y en lo posible consensuada, de España a la modernización y el progreso. ${ }^{10}$ Especializado en relaciones internacionales (desempeñó en varias ocasiones las carteras de Estado, Guerra y Ultramar), culminó su doble andadura política y literaria en 1834 , con apenas cuarenta y tres años de edad, en que simultáneamente alcanzó la presidencia del Gobierno español y estrenó en olor de multitudes y con éxito abrumador una de sus obras culminantes, el drama $L a$ conjuración de Venecia.

Entre las líneas de actuación prioritarias de Martínez de la Rosa a su paso por la presidencia del Gobierno (enero 1834-junio 1835) figuran las relaciones internacionales. El granadino pretendía superar en lo posible el aislamiento del naciente régimen liberal español identificado con Isabel II y su opción dinástica, sometidos uno y otra al cerrado cerco liderado por las grandes potencias legitimistas Austria, Prusia y Rusia, cerco al que se sumaron estados de su entorno ideológico, entre los cuales la Santa Sede, cuya proyección exterior, como ya ha quedado referido, se hallaba muy mediatizada por Viena. El enfriamiento de relaciones de España con la Curia papal respecto a las mantenidas en tiempos de Fernando VII a la vista de la nueva realidad española determinó, de entrada, el relevo de los respectivos representantes diplomáticos. El embajador Pedro Gómez Labrador, de manifiestas inclinaciones pro-carlistas, fue sustituido por Eulogio Pérez de Castro, liberal pero de tendencias moderadas

8 Martínez de la Rosa, F.: Obras. Edición y estudio preliminar de Carlos Seco Serrano. Madrid: Rivadeneyra, 1962 (BAE, ts. 148-155).

9 Marichal, C. 1980. La revolución liberal y los primeros partidos políticos en España: 1834-1844: 84-107 Madrid: Ediciones Cátedra; Cánovas Sánchez, F. 1982. El Partido Moderado. Madrid: CEC; Burdiel, I. 1987. La política de los notables. Moderados y avanzados durante el régimen del Estatuto Real. Valencia: Instituto "Alfons el Magnain"; Sánchez, R. 2000. "La historia del siglo XIX desde la perspectiva moderada: reflexiones de Antonio Alcalá Galiano sobre España". Hispania (CSIC) LX-1: 289-314; Sánchez, R. 2005. Alcalá Galiano y el liberalismo español. Prólogo de J.A. Martínez Martín. Madrid: CEPC.

10 De entre la amplia bibliografía sobre Martínez de la Rosa son aportaciones especialmente reseñables, entre otras: Rebello da Silva, L.A. 1864. Memoria sobre la vida política y literaria de D. Francisco Martínez de la Rosa. Madrid (1a ed.: Lisboa, 1863); Decarretc, Á.Ma . 1885. Martínez de la Rosa. Madrid: Ateneo de Madrid; Sarrailh, J. 1930. Un homme d'Êtat espagnol: Martínez de la Rosa (1787-1862). Bordeaux: Bibliotheque de l'École de Hautes Études Hispaniques; Sosa, L. de 1930. Martínez de la Rosa, político y poeta. Madrid: EspasaCalpe; Godart, L. 1962. Martínez de la Rosa. Ses oevres et sa vie. París: Plon, imp.; Moreno Alonso, M. 1979. Historiografía romántica española. Introducción a la Historia del siglo XIX: especialmente 553557 Sevilla: Univ. de Sevilla; Pérez de la Blanca Sales, P. 2005. Martínez de la Rosa y sus tiempos. Prólogo de Juan C. Gay Armenteros: 316ss. Barcelona: Ariel. 
próximas a las de Martínez de la Rosa, y por tanto considerado adecuado por éste para trabajar con éxito en pro de un reconocimiento pontificio de Isabel II.

En tanto Pérez de Castro llegaba a Roma, sus funciones fueron asumidas por Paulino Ramírez de la Piscina, secretario de la Embajada, y más tarde, al renunciar Pérez a su cargo, le sustituyó como encargado de negocios José Narciso Aparici, uno de los dignatarios de la representación española destacada cerca de la Santa Sede. ${ }^{11}$ En cuanto a la Nunciatura en Madrid, como ya hemos referido, su titular Francesco Tiberi, muy identificado con el desaparecido sistema fernandino, y promovido al cardenalato en premio a sus servicios, dio paso a Luigi Amat, veterano diplomático pontificio que se presentó en Madrid con instrucciones específicas de mantener una actitud neutral ante la cuestión dinástica, sin perjuicio de procurar en lo posible un normal funcionamiento del aparato eclesial español. Empeño difícil, por no decir imposible, dado que Amat no pudo obtener el preceptivo plácet oficial a su nombramiento en tanto Gregorio XVI no reconociese a Isabel II, de igual forma que Pérez de Castro no lo obtuvo en Roma como embajador de España. En consecuencia uno y otro tuvieron que funcionar solamente de forma oficiosa. ${ }^{12}$

La propuesta pontificia de separar las cuestiones políticas de las eclesiásticas al objeto de poder resolver asuntos urgentes, sin que ello conllevara un reconocimiento explícito de Isabel como reina de España, aunque rechazada en Madrid, en la práctica funcionó de forma implícita durante la gestión gubernativa de Martínez de la Rosa, no obstante el plan reformista de las instituciones eclesiales puesto en marcha por el granadino de forma unilateral, y por tanto con el consiguiente rechazo por Roma. Un plan, que diseñado por Nicolás María Garelli Battifora, titular de Gracia y Justicia, aunque recortado por el premier granadino, abocó las relaciones con la Santa Sede al borde de la ruptura, que por el momento no se produjo. Tal ruptura llegaría bajo los efectos de la drástica intensificación de la doble ofensiva exclaustradora y desamortizadora desplegada por los gobiernos que siguieron a la marcha de Martínez, presididos por el conde de Toreno y Mendizábal, y luego durante la Regencia esparterista, que determinaron el corte de relaciones entre ambos estados, relaciones no reactivadas definitivamente hasta la caída de Espartero en 1843.

Por de pronto, la actuación reformista-secularizadora de Martínez de la Rosa bajo la presión de la guerra civil y del distanciamiento de una parte importante del clero respecto a la causa liberal-isabelina, coincidiendo con los primeros meses de su mandato (enero-septiembre de 1834), etapa inmediatamente anterior a la correspondencia aquí presentada, y no obstante su manifiesta voluntad de llegar a acuerdos negociados con la Santa Sede y de recortar disposiciones más radicales de sus ministros y colaboradores, en particular las de Garelli y Toreno, titulares de Gracia y Justicia y de Hacienda, ${ }^{13}$ se tradujo en un conjunto de ini-

11 Archivo del Ministerio de Asuntos Exteriores (AMAE), Sec. Estado (Santa Sede), a. 1833-1834.

12 Archivo Secreto Vaticano (ASV), AA.EE.SS, S. II (Spagna), legs. 161-163, y ASV, ANM, leg. 293 (Nunz. di Tiberi e Amat), 1827-1837.

13 Sobre Torenoysu actuación en este período, véase Varela SuanzesCarpegna, J. 2005. El conde de Toreno. Biografía de un liberal (1786-1843). Prólogo de M. Artola: 161-186. Madrid: Marcial Pons Ediciones. ciativas de alcance nada desdeñable. Ya en 27 de enero del 34 , apenas semana y media después de su toma de posesión, una Real orden dirigida a los cuadros jerárquicos de ambos cleros secular y regular ${ }^{14}$ les exhortaba a mantenerse vigilantes con sacerdotes y frailes para que éstos no desorientasen al pueblo con opiniones erráticas, incluidas las que en el ámbito político pudieran alejarle del preceptivo acatamiento del régimen legítimo encarnado por la reina niña y su Gobierno.

A esa siguieron otras Reales órdenes en igual dirección, pero más tajantes, al tener que ser reprimidos abusos y defecciones concretas en favor de la causa insurgente. Incluido un duro apercibimiento al cardenal primado Pedro de Inguanzo, arzobispo de Toledo. Disposiciones esas, que, a la vista de la desafección de figuras destacadas del clero secular (entre otros el aragonés Antonio Allué, patriarca de las Indias, que hubo de ser destituido, sustituyéndole Manuel Fraile, obispo de Sigüenza y merecedor de la confianza gubernativa) y de varias comunidades conventuales en todo o en parte, dieron paso a decretos de abierta represión dirigidos contra los desafectos y su entorno. ${ }^{15}$

Sin duda las disposiciones más contundentes fueron las emanadas de la Secretaría de Gracia y Justicia, y por tanto suscritas por su titular Nicolás Mạ. Garelli. De entre ellas cabe destacar las siguientes:

\begin{abstract}
"Supresión de la provisión de canonjías, prebendas y otros beneficios eclesiásticos que no conllevasen cura de almas, y asignación de sus dotaciones y rentas a cubrir obligaciones estatales". ${ }^{16}$

"Extinción de monasterios y conventos, e incluso de congregaciones religiosas en bloque, que auxiliasen o colaboraran de alguna forma con el pretendiente carlista, y consiguiente ocupación de sus bienes y temporalidades, cuyo producto sería destinado a enjugar la Deuda pública, desbordada por causa de los gastos de guerra". ${ }^{17}$
\end{abstract}

14 Véanse ese y otros acuerdos en Nieva, J.Mạ. de (ed.) 1835. Decretos de la Reina Nuestra Señora Doña Isabel II, dados en su Real nombre por su Augusta Madre la Reina Gobernadora, y Reales órdenes, resoluciones y reglamentos generales expedidos por las Secretarías del Despacho Universal desde 1ㅇ de enero hasta fin de diciembre de 1834. Madrid: Imprenta Real, t. XIX; y en Diario de Sesiones de las Cortes. Estamento de Procuradores. Legislatura de 1834-1835. Madrid. Imp. de J.A. García. 1867.

15 El contexto histórico de esa labor legislativa en materia eclesial puede verse en las excelentes aproximaciones globalizadoras disponibles. Entre otras: Cuenca Toribio, J.M. 1971. La Iglesia española ante la Revolución liberal: 15-28 Madrid: Rialp; Cárcel Ortí, V. 1975: 218-263.; Revuelta González, M. 2010: 197-334; En cuanto al marco jurídico-político, son monografías básicas, entre otras: Suárez Verdaguer, F. 1958. La crisis política del Antiguo Régimen en España (1800-1840). 2a ed. Madrid: Rialp; Tomás Villarroya, J. 1968. El sistema político del Estatuto Real (1834-1836). Madrid: IEP; Artola, M. 1973. La burguesía revolucionaria (1808-1869): 179-195 Madrid: Alianza Ed.-Alfaguara; Artola, M. 1975. Los orígenes de la España Contemporánea. 2a ed. Madrid: IEP, vol. I (2 vols.); Artola, M. 1991. Partidos y programas políticos, 1808-1936. Madrid: Alianza Editorial, vol. I, (2 vols.); Fontana, J. 1977. La Revolución liberal. (Política y Hacienda -1833-1845-). Madrid: IEF; Nieto, A. 1996. Los primeros pasos del Estado constitucional. Historia administrativa de la Regencia de María Cristina. Barcelona: Ariel. Monografías todas ellas que, aparte de sus respectivas aportaciones específicas, remiten a amplias fuentes documentales y bibliográficas.

16 Nieva, J.Ma. de (ed.) 1835: 132 (Real decreto, 9 marzo 1834).

17 Ibídem, 170-173 (R. decreto, 26 marzo 1834). 
"Constitución de una Real Junta Eclesiástica ${ }^{18}$ no consensuada con Roma, que impulsara y coordinase la reforma eclesial en España, o lo que es igual "el arreglo del clero". ${ }^{19}$

A esas disposiciones cabe sumar otras varias decretadas por las restantes secretarías o ministerios, a su vez incidentes en sentido restrictivo o represivo, según cada caso concreto, sobre el clero, sus derechos y libertades, y sobre su patrimonio. En particular las emanadas de los departamentos de Hacienda, Guerra y Estado, a cargo de José Imaz Altolaguirre, Antonio Remón Zarco del Valle y Francisco Martínez de la Rosa (a su vez presidente del Consejo de Ministros), respectivamente.

\section{CONTENIDOS DE LA DOCUMENTACIÓN APORTADA}

En el primero de los tres despachos (12 septiembre 1834) Martínez de la Rosa se dirige al recién llegado Luigi Amat como "nuncio en España", dado que había sido designado como tal por Roma, y su reconocimiento en Madrid se hallaba en trámite. Sin embargo al no haberse otorgado el preceptivo plácet a ese nombramiento en razón de las dificultades ya apuntadas, en los dos comunicados siguientes (octubre de 1834 y enero de 1835) el jefe del Gobierno español se dirigiría al mismo como "arzobispo de Nicea", que era el título episcopal que ostentaba como pro-nuncio o nuncio en funciones.

Esta misiva inicial ${ }^{20}$ la abre su autor con excusas por su tardanza en responder al primero de los despachos que le dirigiera el enviado del pontífice, retraso que da a entender obedecía a verse desbordado por las obligaciones inherentes a su recién ocupado cargo. En la misma lamentará la presente “... suspensión o entorpecimiento en las relaciones

18 Ibídem, 210-214 (R. decreto, 22 abril 1834).

19 La componían diez obispos y cuatro seglares. De entre los primeros solo cinco eran prelados en ejercicio con sede en España: el mencionado M. Fraile, obispo de Sigüenza y patriarca de las Indias, e Hipólito Sánchez Rangel, Felipe González Abarca, Félix Torres Amat y Lorenzo Ramo de San Blas, titulares de Lugo, Santander, Astorga y Huesca. De entre los otros cinco, a Pedro José Ponte, arzobispo de México refugiado en España, le correspondió la presidencia de la Junta, siendo los restantes dos prelados también desposeídos de sus sedes (Antonio Posada y Pedro González Vallejo, ex-titulares de Cartagena y Mallorca) y dos solamente propuestos pero no confirmados (Vicente Ramos García y Mariano Liñán, de Almería y Teruel respectivamente). De esos diez prelados, tres pertenecían al clero conventual: el franciscano Sánchez Rangel, el mercedario González Abarca y e escolapio Ramo de San Blas. En cuanto a los seglares miembros de la Junta, lo eran Juan Nepomuceno San Miguel, fiscal del Tribuna Supremo; los vocales del Consejo Real Ignacio Pezuela y Tomás González Carvajal, y José Alcántara Navarro, en funciones de secretario de la Junta. Todos ellos individuos liberal-moderados y por tanto de confianza para el presidente del Gobierno y el ministro Garelli, quienes les designaron sin control alguno de las Cortes, y por tanto poco o nada representativos, aparte de hallarse alejados del talante ideológico imperante de forma mayoritaria entre el clero español del momento.

La actuación de la Junta suscitó amplia oposición en el sector progresista, en el cual supo a poco las reformas emprendidas. Pero sobre todo en ambientes eclesiales y no eclesiales ultramontanos, y en definitiva pro-carlistas, al punto de tacharla de ilegítima e incluso cismática. Fue suprimida en febrero de 1836. Sobre la Real Junta Eclesiástica, su composición y actuación, véanse entre otros: Revuelta González, M. 2010: 219-25; Cárcel Ortí, V. (ed.) 1982: 248-52; Cuenca Toribio, J.M. 1971: 15-69.

20 Véase apéndice I. habituales entre España y la Santa Sede", lo cual no sucedería si “... se hubiera decidido el Gobierno de Su Santidad a reconocer en debida forma a la Reina mi S[eñora], en cuyo caso se hubieran allanado por sí mismas en el mismo día las dificultades que han dado origen a la comunicación de V.E. y a esta contestación".

Martínez añade en su respuesta que sin un formal reconocimiento de Isabel II como reina de España no era posible recibir al enviado papal en calidad de nuncio, dado que sus atribuciones como tal conllevaba una jurisdicción religiosa sobre los creyentes españoles que, con frecuencia, tenía "efectos civiles". Por tanto, era desestimada la propuesta de Roma, transmitida por Amat, en el sentido de que éste desglosaría sus funciones eclesiales de su condición de representante de una potencia extranjera, de forma que pudiera ejercer las primeras sin asumir la segunda. Pretensión tanto más inaceptable en Madrid a la vista de la actitud nada favorable, e incluso hostil, del pontífice Gregorio XVI hacia el legítimo régimen español encarnado por la hija y heredera de Fernando VII, hostilidad manifestada con gestos tales como mantener vacantes sedes episcopales en España con el consiguiente daño espiritual de los diocesanos al no confirmar como obispos a los propuestos desde Madrid de acuerdo con los usos establecidos, a diferencia de la actitud indulgente adoptada en América en situaciones similares con las provincias españolas insurreccionadas, cuya independencia de facto ya había sido reconocida por la Santa Sede.

Pero como quiera que en Madrid se estimaba que el reconocimiento de Isabel II por Roma era algo inevitable y por tanto cuestión de tiempo, Martínez de la Rosa y el Gabinete presidido por el mismo se avenían a que el pontífice y su enviado ejercieran sus funciones eclesiásticas en España, al margen de la dimensión política de la cuestión planteada, funciones que deberían ser atendidas de forma puntual y sin reservas ni excepciones. En consecuencia, advertirá a Amat, "... ya que como Soberano temporal [el Papa] suspende el reconocimiento de la Reina mi Señora (aunque no sea fácil concebir las razones en que semejante suspensión puedan apoyarse), como Padre espiritual de los fieles se digne restablecer las antiguas y acostumbradas relaciones, quedando libre y expedito el curso de los negocios eclesiásticos, desde la importante confirmación de los $\mathrm{R}$ [everendos] Obispos hasta otros asuntos de menor gravedad, con arreglo todo a los Concordatos vigentes". ${ }^{21}$

Queda claro que la provisión de las vacantes diocesanas era la cuestión prioritaria a resolver con la Santa Sede sin esperar a que se llegase a un restablecimiento pleno de las relaciones diplomáticas. En aquel momento las vacantes eran seis, producidas escalonadamente desde 1831 por fallecimiento de sus titulares: Zamora, Osma, Teruel, Zaragoza, Almería y Puerto Rico. La ausencia de autoridad diocesana imposibilitaba un normal funcionamiento de los respectivos obispados, con los consiguientes efectos perturbadores no solo en el plano pastoral sino también en el político con la consiguiente desviación de fondos al campo carlista e incluso la defección de numerosos clérigos al hallarse en país subsumido en plena guerra civil. Se comprende que Martínez de la Rosa diese tanta prioridad a este asunto, que llevó personalmente durante el año y medio de

\footnotetext{
21 ĺdem.
} 
su mandato, y muy en especial a partir del verano de 1834 en que, de acuerdo con José Narciso Aparici, agente español en Roma, consideró llegado el momento de afrontar de lleno esta cuestión. ${ }^{22}$

Transcurridas seis semanas desde la misiva inicial del jefe del Gobierno español a L. Amat, no se vislumbró acuerdo alguno. Antes al contrario el distanciamiento se profundizó por causa de las ya referidas iniciativas secularizadoras emprendidas por aquel, sobre todo las de orden económico al intensificarse una contienda civil de desenlace cada vez más incierto. Martínez de la Rosa responderá en 26 de octubre a varias misivas cursadas en ese intervalo de tiempo por Amat, a quien se dirigirá ahora no ya como nuncio sino casi a título particular como arzobispo de Nicea, y conceptuando su despacho ${ }^{23}$ como "nota confidencial". En ella el gobernante español se remitía a una misiva enviada por el secretario de Estado, Bernetti, a Aparici, el encargado de negocios español en Roma, expresando la favorable disposición del pontífice a la resolución de los asuntos eclesiásticos en España, soslayándose por el momento la cuestión del reconocimiento político. En ella Bernetti se mostraba conforme en la resolución del tema de la confirmación de los obispos propuestos por el Gobierno español para cubrir las diócesis vacantes, “... siempre -son palabras suyas ${ }^{24}$ que de los informes que S[u] S[anti]dad tome respecto de ellos resulte que se hallan adornados de las cualidades que se requieren para el Episcopado".

Dando por sentado Martínez de la Rosa que la totalidad de los candidatos propuestos por España eran dignos y aceptables, expresaría su satisfacción porque Roma, al fin, se aviniera a proceder a los nombramientos de acuerdo con la práctica establecida, soslayándose las cuestiones políticas. Pero, y ahora era la parte española la que ponía condiciones, siempre y cuando en las bulas pontificias de confirmación de los nuevos prelados según las normas establecidas, aunque se omitiera el nombre del monarca que hacía la propuesta (Isabel II), ello no dejase de conllevar un reconocimiento implícito de su legitimidad como soberana española. Concesión la suya que Madrid esperaba fuese valorada adecuadamente en al Curia pontificia, y en palabras de Martínez a Amat “... probará a V.E. hasta qué punto desea el Gobierno español facilitar por su parte los medio de hacer cesar el estado actual de cosas, respecto de un punto de tanta trascendencia; y no dudo que coadyuvando V.E. por su parte, como me lo hace esperar el elevado concepto de su carácter y sus sentimientos conciliativos, se proveerá de remedio a los males que resultan de hallarse por tanto tiempo vacantes varias sillas episcopales". Por el momento, el silencio fue la respuesta.

Transcurridos tres meses sin que las relaciones hubiesen experimentado mejoría alguna, sino que, por el contrario, se vieron agravadas por la acumulación de contenciosos pendientes, y continuando aparcada la fundamental cuestión de la confirmación por Roma de los nombramientos episcopales propuestos por el Gobierno español, Martínez

22 Sobre las gestiones de J.N. Aparici cerca del secretario de Estado pontificio T. Bernetti en relación con la cuestión de referencia, y el desarrollo de las mismas, y sobre el asunto de las vacantes diócesis en general, véase Cárcel Ortí, V. (ed.) 1982: XLVI-LV.

23 Véase apéndice II.

24 Cfr. I ĺdem. de la Rosa, a instancias de la reina gobernadora María Cristina de Borbón, de la que dice hacerse portavoz, dirigirá un despacho personal ${ }^{25}$ al representante papal en Madrid, a quien continuaba refiriéndose como arzobispo de Nicea, que no como nuncio, carácter que todavía no le había sido reconocido. El español le apremiará a llegar cuanto antes a acuerdos que posibilitasen, siquiera, el arreglo de los asuntos pendientes de más urgente resolución, comenzando por la provisión de las sedes episcopales vacantes.

A tal fin el jefe del Gobierno español proponía una vez más el recurso a una fórmula en esos nombramientos que, sin cuestionar la legitimidad de doña Isabel como soberana española, no se la mencionase como tal de forma expresa, solución practicada ya por la Santa Sede en varios documentos de oficio referidos a España (dispensas matrimoniales, etc.), al objeto de que no tuviera que ser vetada su circulación. Sugería que la aplicación de esa u otra fórmula similar se hiciera extensible a documentos de superior solemnidad y trascendencia como eran, en efecto, las bulas de confirmación de obispos. Y añadirá que, siendo evidente la existencia de un cierto consenso entre ambas partes sobre la conveniencia de no prolongar por más tiempo la no provisión de sedes episcopales vacantes por el daño que tal situación conllevaba para todos, sugería como solución el uso de fórmulas que soslayasen "la cuestión política del reconocimiento", recurriéndose a "... alguna frase general acomodada al obgeto (sic) de que ni vulnerase ningún derecho ni prejuzgase ninguna cuestión". ${ }^{26}$

Abundando en ello, Martínez mencionaba varios modelos al uso, en los cuales se hacía referencia al monarca español de forma genérica y sin expresar su nombre concreto. Solución ésta que consideraba aplicable a documentos importantes como los nombramientos de referencia. Entendía que para el Gobierno español no eran de recibo soluciones alternativas a las que en ocasiones recurría Roma, tales como la delegación de competencias por el pontífice en el arzobispo de Toledo u otros intermediarios en relación con casos concretos, según había ocurrido al designar sucesor del recientemente fallecido comisario general de Santa Cruzada. El premier español confiaba en que se llegase a una solución satisfactoria para ambas partes, dados los daños añadidos que se derivarían en el caso de prolongarse tan anómala como lamentable situación. De otro lado entendía no ser de recibo más demoras, en razón del malestar general que suscitaba entre el pueblo español y sus gobernantes la negativa actitud de la Santa Sede, advirtiendo además haber llegado el Gobierno de España “... hasta el límite a que le conduce el anhelo de hallar medios de conciliación, y del cual no pudiera pasar sin faltar a su propio deber y comprometer su decoro...". En consecuencia, y habida cuenta la buena voluntad presumible en ambas partes para llegar a acuerdos conciliatorios y dignos, confiaba en que ello posibilitaría “... en cuanto a las graves materias que están pendientes en el día entre la S[an] ta Sede y el Gobierno español, (...) acelerar su terminación de un modo igualmente justo que decoroso para entrambas partes". ${ }^{27}$

\footnotetext{
25 Véase apéndice III.

26 Ídem.

27 Ídem.
} 
Esto refería Martínez de la Rosa en 14 de enero de 1835. Que por circunstancias diversas su propuesta no tuvo en Roma la acogida deseada lo evidencia el que transcurriese casi medio año sin llegarse a solución alguna concreta, solución que el estadista español no alcanzó a ver desde su Gobierno, que en 7 de junio siguiente dio paso a otro presidido por el conde de Toreno. Agravadas las relaciones entre España y la Santa Sede bajo el impacto de la triple ofensiva secularizadora, exclaustradora y desamortizadora llevada hasta sus últimas consecuencias por los siguientes Gabinetes de signo progresista-radical, el asunto de la provisión de las diócesis españolas vacantes, así como otros contenciosos pendientes, no alcanzarían una solución estable y definitiva hasta avanzada la década de 1840, ya durante el pontificado de Pío IX y con el general Ramón Mạ. Narváez y su conservador Partido Moderado sólidamente instalados en el poder, circunstancias que posibilitaron la normalización plena de las relaciones del Reino de España con la Santa Sede en el marco del Concordato de $1851,{ }^{28}$ Ilamado a mantener su vigencia, salvo breves paréntesis, durante un siglo.

\section{APÉNDICE DOCUMENTAL}

I. Sobre el no reconocimiento de Isabel II como reina de España por la Santa Sede. Su negativa incidencia en un normal funcionamiento de las instituciones eclesiales de la nación española y posibles soluciones (septiembre, 1834). ${ }^{29}$

\section{“Excmo. Señor,}

Muy Señor mío:

Debo ante todas cosas disculparme a los ojos de V[uestra] E[xcelencia] por no haber contestado antes al recuerdo-sic ${ }^{30}$-que se ha servido dirigirme con fecha 25 del pasado, instando nuevamente para que se termine el punto en discusión, acerca de admitir a V.E. en calidad de Nuncio de Su Santidad; pero la bondad de V.E. habrá hallado la escusa de mi involuntario retardo en el cúmulo de negocios que me impone mi deber en las presentes circunstancias.

Tal vez me [f. 1v] había también lisongeado (sic) la esperanza de que, hecho cargo el Gobierno de S[u] S[antid]ad ${ }^{31}$ de los indisputables derechos de la Reina mi Señora al Trono de su Augusto Padre, ${ }^{32}$ en virtud de las leyes fundamentales

28 Pérez Alhama, J. 1967. La Iglesia y el Estado español. Estudio histórico-jurídico a través del Concordato de 1851. Madrid: IEP; Castillo y Ayensa, J. del 1859. Historia crítica de las negociaciones con Roma desde la muerte del Rey Don Fernando VII. Madrid: Ed. Tejado, 2 vols.; Suárez Verdaguer, F. 1963. "Génesis del Concordato de 1851", Ius Canonicum, III, fasc. 1-2: 65-149; Suárez Verdaguer, F. 2002. "El anticlericalismo español en el siglo XIX", en P. Aubert (ed.), Religión y sociedad en España (siglos XIX y XX): 155-178. Madrid: Casa de Velázquez. Véanse, a su vez, las fuentes documentales y bibliográficas citadas en notas 1, 4, 5, 9 y 15 supra.

29 ASV, ANM, leg. 293 (Nunziaturas di Monss. Tiberi e Amat, 1827-1837): F. Martínez de la Rosa a L. Amat, pro-nuncio en España y arzobispo de Nicea, Madrid 12 septiembre 1834.

30 Oficio o despacho.

31 Mauro Cappelari, papa Gregorio XVI entre 1831 y 1846 Próximo a la opción carlista. Véase nota 3 supra.

32 Fernando VII, rey de España, 1808-1833. de la Monarquía, ${ }^{33}$ y no en virtud de una innovación en el orden de suceder, ${ }^{34}$ como equivocadamente se ha repetido; conocida mejor la voluntad general de la nación a favor de los mismos derechos; y esperando el S[an]to Padre en su prudencia y sabiduría los graves perjuicios espirituales $q[u]$ e pueden seguirse y acrecentarse con la continuación de la situación actual [f. 2r] de España respecto de la Santa Sede, se hubiera decidido el Gobierno de Su Santidad a reconocer en debida forma a la Reina mi S[eño]ra, en cuyo caso se hubieran allanado por sí mismas en el mismo día las dificultades que han dado origen a la comunicación de V.E. y a esta contestación.

Basta la razón indicada para probar que el Gobierno español ha estado lejos de oponerse a la admisión de un representante de S. Sad.; que tampoco ha habido ni remotamente intención ni deseo de dar a esta cuestión un carac[f.2v]ter personal que no tiene, siendo tan al contrario que el Gobierno español reconoce y aprecia las distinguidas cualidades que adornan al digno Prelado nombrado por $\mathrm{S}$. $\mathrm{S}^{\text {ad. }},{ }^{35}$ y que cualesquiera que sean los perjuicios que puedan originarse de esta suspensión o entorpecimiento en las relaciones habituales entre España y la Sta. Sede, ${ }^{36}$ la responsabilidad no pesará en ningún caso sobre el Gobierno de $\mathrm{S}[\mathrm{u}] \mathrm{M}$ [ajestad], que no ha suscitado el obstáculo, y que antes bien ha instado para que se renueven y se estrechen más cada día los vínculos amistosos [f. 3r] entre ambas Potencias.

Lo que no es fácil concebir ni explicar es cómo la Corte de Roma retarda o suspende reconocer al Gobierno legítimo establecido en España, al paso que insta para que este mismo Gobierno admita a un Representante de la Sta. Sede, y le dege (sic) ejercer en estos Reinos una jurisdic[c]ión q[u] e somete a sus fallos a los súbditos de S.M., y que causa efectos civiles.

Mas aunque se quisiese decir que la persona del R[evren] do Nuncio de S. S $\mathrm{S}^{\text {ad. }}$ puede considerarse bajo dos caracteres distintos, y que es dable admitir en él [f. 3v] al que ha de ejercer una Autoridad espiritual, sin que por eso se le considere como representante de un Soberano extrangero (sic) cerca de nuestra Corte (como parece indicarse en la memoria que V.E. ha tenido a bien remitirme) $;{ }^{37}$ y aun cuando se pudiese admitir la separación de uno y otro carácter, siempre saltaría a los ojos una reflexión importantísima, bastante por sí sola para justificar plenamente la conducta observada en este punto por S.M.

33 Orden sucesorio tradicional castellano fijado por Las Partidas, en el cual la mujer no es postergada, sistema anulado por Felipe $V$ con la francesa Ley Sálica, pero restablecido por Carlos IV y Fernando VII con la Pragmática Sanción.

34 Referencia a la Pragmática Sanción.

35 Luigi Amat di San Philippo e Sorso, arzobispo de Nicea, llegado a Madrid en septiembre de 1833 como sustituto del nuncio Francesco Tiberi, pero a quien el Gobierno español por el momento negó el pase regio, y por tanto el rango de embajador.

36 Suspensión fáctica de relaciones por las reticencias de la Santa Sede a reconocer formalmente a Isabel II como soberana legítima de España, no obstante gestos de aproximación, y de no haber reconocido tampoco a don Carlos, con quien eran mantenidas relaciones oficiosas similares a las sostenidas con los gobiernos de Madrid.

37 No conservada en AMAE, Estado (Santa Sede), a. 1833-1834, pero sí referencias a sus contenidos en el archivo de la Nunciatura en Madrid. Véase Cárcel Ortí, V. (ed.) 1982: 262ss. 
En efecto, ¿cómo se pretende que el Gobierno [f. 4r.] español separe las dos consideraciones antes indicadas, cuando por parte de la Corte de Roma no se le da el ejemplo? Si S. Sad. en calidad de Monarca temporal suspendiese por razones políticas el reconocimiento de la Reina mi Señora, ${ }^{38}$ pero al mismo tiempo como Pastor y Padre de los fieles acudiese a las necesidades de la Iglesia de España, mayores en estos tiempos y de atención urgente; si no retardase la confirmación de los virtuosos Prelados presentados por S.M. para ocupar las Sillas vacantes, ${ }^{39}$ con perjuicio de la religión y [f. 4v] del Estado, al paso que parece sigue S. S $\mathrm{S}^{\text {ad. }}$ una conducta diferente con las personas que le presentan con igual obgeto (sic) los Gobiernos efímeros que se levantan y se destruyen sucesivamente en las Provincias de América; ${ }^{40}$ si cuando se promueve la guerra civil en España, ${ }^{41}$ alarmando la piedad de la gente sencilla, se oyese resonar la voz del Pastor de los fieles, excitando el fervor del clero, y exhortando a los españoles, parte preciosa del rebaño de Jesucristo, para que no se destruyan $\mathrm{y}$ aniquilen peleando hermanos [f. $5 \mathrm{r}$ ] contra hermanos, entonces sería el caso de instar al Gobierno español para que hiciese esa segregación y deslinde entre las facultades que competen al $\mathrm{R}^{\text {do. }}$ Nuncio nombrado por $\mathrm{S}$. $\mathrm{S}^{\text {ad. }}$ en calidad de Delegado de la Autoridad Pontificia, y los derechos y prerrogativas que le corresponden como Encargado de representar a un Soberano.

Se dice en la memoria o escrito que V.E. ha tenido la bondad de comunicarme, que no hallándose todavía S. Sad. en el caso de reconocer a la Reina mi Señora, “... no pide que el $M\left[\right.$ [uy] $R^{\text {do. }}$ Arzobispo de Nicea [f. 5v] sea reconocido como uno de los Diplomáticos que representan a sus respectivas Cortes en Madrid". Es evidente, Excmo. Sor. que tal no pod[r] ía ser nunca la intención ni el deseo de un Gob[ier]no tan ilustrado como el de S. Sad.; pues que por los primeros elementos del derecho de gentes, por la práctica común y constante, y hasta por lo que dicta la sana razón, no puede haber un agente diplomático acreditado cerca de un Gobierno que no sea reconocido como tal; ni es posible concebir qué clase de relaciones mutuas pudieran existir en una suposición tan imposible [f. 6r] de realizarse.

Mas en la citada memoria se añade que “... lo que reclama S. Sad. es que (dicho dignísimo Prelado) sea reconocido como Legado Pontificio, provisto de las facultades ordinarias y extraordinarias que han acostumbrado egercer (sic) los Nuncios Apostólicos, y que nada tienen que ver con el suspendido reconocimiento".

Sin entrar de lleno en esta cuestión, y limitándola al terreno mismo indicado por V.E. con arreglo al mandato de su Corte, daré a V.E. la contestación que me ha prescrito

38 Isabel II todavía no había sido reconocida por Roma como reina de España de forma explícita, sino solo implícitamente, actitud similar a la adoptada respecto a don Carlos.

39 Seis en total, las de Almería, Gerona, Osma, Teruel, Zamora y Puerto Rico, vacantes por fallecimiento de sus titulares entre diciembre de 1831 y mayo del 34. Véase Cárcel Ortí, V. 1982: XLVIII, nota 82.

40 En los territorios de la América continental independizados de España, estatus ese por el momento no reconocido por la ex-metrópoli. Sobre el nombramiento de obispos por Roma en esos territorios véase Instrucciones de la Sagrada Congregación de Asuntos Eclesiásticos Extraordinarios a Mons. L. Amat di San Filippo, Roma 19 agosto 1833, en Cárcel Ortí, V. (ed.) 1982: 333-335.

41 Primera Guerra Carlista, 1833-1840.
S.M. la Reina Gobernadora, ${ }^{42}$ llevada del sincero deseo de allanar dificultades y obstáculos, y de que se adopte un medio conciliatorio, conforme con los verdaderos principios, y que reúna todos los intereses.

Su Santidad, como Soberano temporal, puede usar del libre derecho de suspender o no el reconocer a un Gobierno establecido en otro Reino; y S.M. ha estado tan lejos de querer vulnerar o coartar ese egercicio (sic) de la Soberanía, que es la primera en respetarlo, y ha dado a sus agentes diplomáticos en las Cortes extrangeras (sic) instrucciones análogas a ese mismo principio.

Mas si [f. 7r] S. Sad. (dejando a un lado las relaciones políticas suspendidas entre ambos reinos) desea que se atienda meramente a su Sagrado carácter de Cabeza Visible de la Iglesia, admitiendo en España bajo ese concepto a su Nuncio Apostólico, la justicia, la imparcialidad y el bien mismo de la Iglesia y del Estado exige que se trace una línea entre los dos caracteres que reúne la Augusta Persona de Su Santidad; y que ya que como Soberano temporal suspende el reconocimiento de la Reina mi Señora (aunque no sea fácil concebir las razones en que semejante suspensión pueda apoyarse), como Padre espiritual de los fieles se digne [f. 7v] restablecer las antiguas y acostumbradas relaciones, quedando libre y expedito el curso de los negocios eclesiásticos, desde la importante confirmación de los R[everen]dos Obispos hasta otros asuntos de menor gravedad, con arreglo todo a los Concordatos vigentes. ${ }^{43}$

Ningún medio más fácil y expedito de hacer cesar cuanto antes un estado de cosas, cuyos perjuicios actuales, y cuyas consecuencias posibles, no se ocultarán a la piedad ilustrada de Su Santidad, [tanto más] no siendo probable que medie razón alguna que pueda oponerse a una medida tan imparcial, [f. 8r] tan equitativa, tan conforme al espíritu y doctrina de la Iglesia.

S.M. se lisongea (sic) de haber dado con esta leal manifestación la prueba más convincente de sus amistosas disposiciones y de su profunda veneración a la S[an]ta Sede; satisfecha con haber procurado conciliar de esta suerte sus obligaciones más sagradas, mirando por la independencia y decoro de la Corona de su Excelsa Hija, cuya guarda le han confiado las leyes, y no desatendiendo [así] por su parte las necesidades espirituales de una Nación [f. 8v] a la par leal y religiosa.

Aprovecho esta ocasión para reiterar a V.E. las seguridades de mi más alta consideración y aprecio.

Dios gu[ard]e a V.E. m[ucho]s a[ño]s. Palacio 12 de Sept[iem]bre de 1834.

Excmo. Señor, B[esa] L[a] M[ano] de V[uestra] E[excelencia] su atento y seg[ur]o servidor, FRANCISCO MARTÍNEZ DE LA ROSA.

Sor. Nuncio de Su Santidad."

42 María Cristina de Borbón-Nápoles, 4ạ esposa y viuda de Fernando VII, madre de Isabel II y reina-gobernadora o regente de España entre 1833 y 1839.

43 Concordato de 1753 suscrito por Fernando VI, revisado y actualizado después en varios puntos concretos durante los reinados de Carlos III, Carlos IV, Fernando VII y etapa inicial de Isabel II hasta la entrada en vigor de un nuevo Concordato en 1851. 
II. Sobre lo mismo. Especial atención a los problemas derivados de la no confirmación por Roma de los candida tos propuestos por el Gobierno español para cubrir las diócesis vacantes (octubre, 1834). ${ }^{44}$

"Excmo. Señor,

Muy Señor mío:

El tenor de las últimas comunicaciones de V.E. y el sincero deseo que anima al Gobierno español de ver allanadas las dificultades que por desgracia entorpecen las relaciones habituales entre la Santa Sede y este Católico Reino (dejando aparte por ahora las relaciones políticas entre uno y otro Estado) me estimulan a dirigir a V.E. esta Nota confidencial sobre un asunto importante de suyo, y que pudiera influir favorablemente en la consecución del fin indicado.

El Encargado de Negocios de España en Roma ${ }^{45}$ ha dirigido recientemente un escrito al Cardenal Secretario de Estado, ${ }^{46}$ Ilamando la atención de Su Santidad hacia los graves perjuicios que se habían ya seguido a la Iglesia, y que podrían acrecentarse, de continuar varias Diócesis huérfanas [f. 1v] de Pastores, por no haber recaído la confirmación de la Santa Sede en las propuestas hechas por el Gobierno español de Eclesiásticos dotados de saber y de virtud, aptos por sus merecimientos para ocupar las Sillas vacantes.

En la contestación, que de orden de S. $\mathrm{S}^{\text {dad }}{ }^{47}$ remitió el Cardenal Secretario de Estado al Encargado de Negocios, se asienta el principio fundamental, que debe ser la clave en estas materias, a saber: que '... dejando a un lado toda mira política extraña a los intereses de la Religión, se atienda a estos, los cuales interesan tan profundamente a Su Santidad como pudieran interesar al Gobierno más religioso'.

En prueba y confirmación de este aserto (tan conforme al sagrado carácter de la Cabeza Visible de la Iglesia) declara

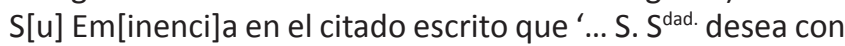
toda sinceridad y eficacia proveer de Obispos las Iglesias vacantes de España, y que no tendrá dificultad en proveer [ $\mathrm{f}$. 2r] dichas Sillas en los mismos Eclesiásticos que el Gobierno español ha propuesto, siempre que de los informes que $S$. $S^{\text {dad. }}$ tome respecto de ellos resulte que se hallan adornados de las cualidades que se requieren para el episcopado'.

Del anterior contexto parecía inferirse que la dificultad no versa sobre el fondo del asunto en cuestión, puesto que S. $\mathrm{S}^{\text {dad. }}$ se halla dispuesto a confirmar los Obispos electos por el Gobierno Español, sino sobre el modo y forma de verificar la previa información, acostumbrada en tales casos.

$\mathrm{S}[\mathrm{u}] \mathrm{Em}$ [inenci]a recuerda, al efecto, que el proceso canónico para cada Obispo electo lo evacua el Rdo. Nuncio de S. $S^{\text {dad. }}$ en estos Reinos; y como el Gobierno español está

44 ASV, ANM, leg. 293 (Nunziaturas di Monss. Tiberi e Amat, 1827-1837): F. Martínez de la Rosa a L. Amat, pro-nuncio en España y arzobispo de Nicea, Madrid, 26 octubre 1834.

45 José Narciso Aparici, secretario de la Legación de España en la Santa Sede, de que se hizo cargo como encargado de negocios tras el fulminante cese del pro-carlista embajador Pedro Gómez Labrador por el Gabinete Martínez de la Rosa, hasta la llegada del nuevo embajador Eulogio Pérez de Castro.

46 Tommaso Bernetti, cardenal secretario de Estado durante el pontificado de Gregorio XVI. Sobre sus relaciones con España véase Morelli, E. 1966. La politica estera di Tommaso Bernetti, segretario di Stato di Gregorio XVI. Roma.

47 No conservada en el expediente ni tampoco en la Sec. Santa Sede del AMAE. pronto en los términos que tuve la honra de manifestar a V.E. en mi Nota de 12 de Septiembre último, ${ }^{48}$ a reconocer a V.E. como tal Nuncio de Su Santidad y a permitirle ejercer su autoridad delegada con arreglo a los Concordatos vigentes, siempre que se [f. $2 \mathrm{v}$ ] restablezcan las relaciones con la Santa Sede (prescindiendo por ahora de involucrar los intereses sagrados de la religión con cuestiones políticas), resulta de estos antecedentes que si V.E. no halla reparo, según las instrucciones que tenga, en formar los procesos canónicos en la forma acostumbrada a los dignos Eclesiásticos propuestos por el Gobierno español para ocupar las Sillas vacantes, este será un medio de adelantar en un asunto tan importante al bien de la Iglesia y del Estado, al paso que ofrecerá el testimonio más convincente de que se está ya en la senda que ha de conducir al término deseado.

Me es sumamente sensible tener que aludir a la segunda dificultad, indicada por S. Em ${ }^{\text {a. }}$ el Cardenal Secretario de Estado; dificultad que, aunque parece de mera forma, puesto que versa sobre los términos en que han de estar concebidas las Bulas de Confirmación, recuerda un punto desagradable de suyo y de naturaleza delicada. Así en [f. $3 r$ ] las varias Notas que he extendido sobre este asunto, en obedecimiento de regio mandato, como en las órdenes e instrucciones que se han dado a los Agentes Diplomáticos de S.M., siempre se ha partido de este principio: que los derechos de la Reina Doña Isabel Segunda, nacidos de las antiguas leyes fundamentales de la Monarquía, restablecidas por su Augusto Padre (Q.E.E.G.), y confirmadas por dos veces por las Cortes Generales del Reino, no dependen para su validez y firmeza del reconocimiento de las Potencias extranjeras; ${ }^{49}$ por cuya razón, si bien este reconocimiento sería grato a S.M., que anhela mantener con todas las Potencias las más sinceras relaciones de amistad y benevolencia, no por eso debían instar para obtenerlo los Agentes Diplomáticos de S.M. en las Cortes extrangeras (sic).

Por lo tanto, como la omisión o alteración de estas o esotras-sic- expresiones en las Bulas no pueden vulnerar en lo más mínimo los incontestables [f. 3v] derechos de S.M. Doña Isabel Segunda al Trono de su Augusto Padre, ni aun desea el Gobierno español que se manifieste (como indica S. Ema. en su citado escrito) que la omisión o alteración que se note en las Bulas que se expidan por $\mathrm{S}$. $\mathrm{S}^{\mathrm{dad}}$. respecto de las anteriores, no se entienda que perjudiquen en manera alguna a los derechos que a cada uno puedan competir, antes bien opina el Gobierno español que, extendidas las Bulas en términos generales que no toquen a las relaciones políticas

48 Véase apéndice I supra.

49 Las potencias legitimistas Austria, Prusia y Rusia se decantaron desde el principio por la opción carlista, arrastrando en esa dirección a los estados a ellas vinculados, entre los cuales la Santa Sede, identificada con Austria en política internacional. Una realidad llamada a subsistir sin grandes cambios hasta mediados de siglo, en que el régimen isabelino, por largo tiempo sin otro apoyo firme que el eje liberal París-Londres, al variar drásticamente la realidad internacional bajo los efectos de la revolución europea de 1848, fue universalmente reconocido. Véanse sendas aproximaciones globalizadoras sobre esta cuestión en Vilar, J.B. 1989: 37-80 y Vilar, J.B. 2003: 401-420 (hay reeds.), que remiten, además a la amplia bibliografía disponible sobre aspectos puntuales (J. de Burgos, marqueses de Villa-Urrutia y Miraflores, J. Bécker, G. Vidal y Saura, J.Ma . Jover, P. Renouvin, Ma.V. López-Cordón, J.S. Leeming, J.C. Pereira, V. Cárcel, J.M. Cuenca, M. Revuelta, M. Rodríguez Alonso, L. Blanchard Rubio, J.R. Urquijo Goitia, C. Nieto Sánchez..., etc.). 
suspensas entre ambos Estados, este será el mejor medio de que aparezca más claro y palpable el deslinde entre las

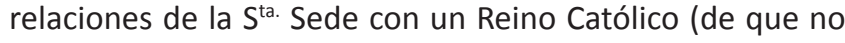
pudiera prescindirse ni aun por corto tiempo sin que pesase una responsabilidad inmensa sobre una y otra Potestad) y las relaciones políticas entre dos Estados independientes, sujetas a consideraciones y miras mundanas.

Esta franca y sincera manifestación probará a V.E. hasta [f. 4r] que punto desea el Gobierno español facilitar por su parte los medios de hacer cesar el estado actual de cosas, respecto de un punto de tanta trascendencia; y no dudo que coadyuvando V.E. por su parte, como me lo hace esperar el elevado concepto de su carácter y sus sentimientos conciliativos, se proveerá de remedio a los males que resultan de hallarse por tanto tiempo vacantes varias Sillas episcopales. Y si me pudiera quedar duda de que en breve cesará un daño de tanta gravedad, me la disiparía cumplidamente las expresiones con que termina su escrito el Cardenal Secretario de Estado: 'S. S $S^{\text {dad. }}$ ha preferido (decía S. Em ${ }^{\text {a. }}$ al Encargado de Negocios) que manifieste a V.S. las dificultades por las cuales no puede S. $\mathrm{S}^{\text {dad. }}$ proveer en el próximo Consistorio algunas de las Iglesias vacantes de España; y que al mismo tiempo le proponga el modo de superarlas, sin perjuicio de los derechos de cada uno, para poder enseguida dar Pastores a dichas Iglesias'. [f. 4v].

Aprovecho con gusto esta ocasión para reiterar a V.E. las seguridades de mi más distinguida consideración.

Dios gue. A V.E. ms. a $^{\text {s. Palacio }} 26$ de Octubre de 1834.

Excmo. Señor, B.L.M. de V.E. su atento seguro servidor, FRANCISCO MARTÍNEZ DE LA ROSA.

Señor Arzobispo de Nicea."

III. Nuevas propuestas de Martínez de la Rosa y del Gobierno español para llegar a una solución satisfactoria para ambas partes sobre los contenciosos pendientes entre España y la Santa Sede (enero, 1835). ${ }^{50}$

"Excmo. Señor,

Muy Señor mío:

Habiendo dado cuenta a S.M. la Reina Gobernadora del estado en que actualmente se hallan las cuestiones pendientes con la Santa Sede, y deseosa S.M. de allanar por su parte (en cuanto lo consientan el decoro de la Corona, y las leyes y fueros de [la] Nación) todas las dificultades que se han suscitado desgraciadamente, y cuya pronta solución interesa no menos al bien de la Iglesia que al del Estado, se ha dignado S.M. ordenarme tenga el honor de comunicar a V.E., como de Real [f. 1v] orden lo egecuto (sic), las disposiciones del Gobierno español, no menos equitativas que conciliadoras, fundadas todas ellas en la base ya adoptada de hacer el conveniente deslinde entre las relaciones políticas de uno y otro Reino, y las que siempre deben mediar entre la Cabeza Visible de la Iglesia y el Reino Católico de las Españas.

Si por una y otra parte se ponen en egecución (sic) las consecuencias de este principio, el Gobierno de S.M. está pronto a admitir a V.E. en calidad de Nuncio Apostólico de S. $\mathrm{S}^{\text {ad. }}$ en la misma forma y con las mismas condiciones $y$

50 ASV, ANM, leg. 293 (Nunziaturas di Monss. Tiberi e Amat, 1827-1834): F. Martínez de la Rosa a L. Amat, pro-nuncio en España y arzobispo de Nicea. Madrid 11 enero 1835. facultades que lo [f. 1v] fueron sus predecesores; prescindiendo por ahora del carácter político, hasta que la Corte de Roma, según es de esperar de su prudencia y sabiduría, reconozca como Reina de España a la Augusta Hija del $S^{r}$. $D^{n}$. Fernando 70, que tantas pruebas dio a la $\mathrm{S}^{\text {ta. }}$ Sede de veneración y benevolencia.

Una vez suspenso el expresado reconocimiento por parte de la Corte de Roma, y tan distante el Gobierno español de querer estrechar a los Gabinetes extrangeros (sic) para la resolución de un punto meramente político, que ni puede robustecer ni [f. 2v] menguar los derechos del legítimo Trono, como celoso de que no se menoscaben las prerrogativas inherentes a la Corona (las cuales son al mismo tiempo un patrimonio de la Nación que no es dado enagenar-sic- ni ceder), no halla inconveniente en que las Bulas que se expidan por la $\mathrm{S}^{\text {ta. }}$ Sede, confirmando a los dignos Eclesiásticos presentados en virtud del Regio Patronato, vengan concebidas con tales expresiones, que al mismo tiempo degen (sic) a salvo una prerrogativa tan esencial, de que nunca prescindieron ni pueden prescindir los Monarcas de España, y eviten a la [f. 3r] $\mathrm{S}^{\text {ta. }}$ Sede el tocar la cuestión política del reconocimiento.

Un medio apropósito para conciliar ambos objetos (sic) (muy análogo a lo que en esta última época se ha practicado, así en la Bula expedida al $\mathrm{R}^{\text {do. }}$ Obispo actual de Canarias ${ }^{51}$ como en los Breves de dispensas matrimoniales dirigidos al Vicario general de los Reales Egércitos -sic-) sería el que se usase en las Bulas de confirmación que hayan de expedirse, alguna frase general acomodada al obgeto (sic) que ni vulnerase ningún derecho ni prejuzgase ninguna cuestión. Tal sería, por ejemplo, la fórmula de [f. 3v] 'Su Magestad (sic) Católica' o de 'Reyes Católicos' cuando se hiciese mención en dichos documentos de los derechos o prerrogativas de la Corona de España. ${ }^{52}$

Habiendo llegado el Gobierno de S.M. hasta el límite a que le conduce el anhelo de hallar medios de conciliación, y del cual no pudiera pasar sin faltar a su propio deber y comprometer su decoro, puede esperarse confiadamente que no habrá el menor reparo por parte de la $\mathrm{S}^{\text {ta. Sede en }}$ expedir las Bulas en los términos expresados, dándose a V.E. la acostumbrada autorización para instruir la información o proceso a los dignos Eclesiásticos presentados por S.M., [f. $4 r$ q que han de ocupar las Sillas vacantes.

Cuando ya, respecto a admitir a V.E. como Nuncio Apostólico en estos Reinos, y respecto a los términos en que pudieran expedirse las Bulas de los Obispos electos, parecía que se había encontrado una línea tan recta como breve,

51 Judas José Romo y Gamboa, presentado por Fernando VII para obispo de Canarias en 2 septiembre 1833 y preconizado por Gregorio XVI en 20 enero 1834. Vid. Cárcel Ortí, V. (ed.) 1982: LIII, nota 96.

52 Privilegio de la Corona española remontable a tiempos de los Reyes Católicos, y que salvo varios paréntesis en etapas de ruptura de relaciones diplomáticas entre España y la Santa Sede, subsistiría hasta 1976, en que durante la presente situación democrática un Gobierno presidido por Adolfo Suárez, invocando la independencia mutua de Iglesia y Estado, renunció a tan trasnochada prerrogativa. Véase, en efecto, Martín de Santaolalla, P. 2013. El rey, la Iglesia y la Transición. Madrid: Silex Ediciones: 87-94. Sobre cuestiones similares (nombramiento de obispos, etc.) durante el Gobierno de Martínez de la Rosa véanse, a su vez, diferentes Actas de la Congregación de Asuntos Eclesiásticos Extraordinarios (diciembre 1834-febrero 1836) en Cárcel Ortí, V. 1982: 340-353. 
que evitase los opuestos inconvenientes y condugere (sic) al término apetecido, ha sido muy sensible al Gobierno de S.M. el nuevo incidente de que acaba de darle cuenta su Encargado de Negocios en Roma, ${ }^{53}$ trastocando la Nota que con fecha 15 de Diciembre del año p[róxi]mo p[asa]do le

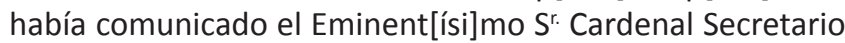
de Estado.

Según el [f. 4v] contexto de dicho documento, aparece que Su Santidad, en contestación a la reverente súplica del Gobierno español solicitando se renovase por el término acostumbrado de diez años el Indulto Cuadragesimal, e indicando la persona en que había recaído el Regio nombramiento de Comisario General de la $\mathrm{S}^{\text {ta. }}$ Cruzada por fallecimiento del que anteriormente lo era, ${ }^{54}$ ha tenido a bien Su Santidad proveer a la necesidad más urgente, concediendo solo la prórroga por espacio de un año, y delegando al efecto la competente facultad en el M[uy] R[everen]do Arzobispo de Toledo. ${ }^{55}$

El Gobierno de S.M. deja a la penetración de V.E. calcular el no esperado [f. $5 r$ ] sentimiento que ha debido causarle (cabalmente en los mismos días en que constan a V.E. sus sinceros deseos de remover obstáculos y desatar dificultades) el ver la escasa acogida que ha tenido en la $S^{\text {ta. }}$ Sede una solicitud fundada en tan poderosas razones, conforme a la práctica de estos Reinos, y que bajo ningún aspecto tenía roce ni contacto con la cuestión política, al paso que versa únicamente sobre un punto fundado en la piedad de los pueblos. Nuevo y poderoso motivo [este] para proceder en tan delicada materia con la mayor circunspección y miramiento.

Por lo tanto el Gobierno español, si bien no puede menos de manifestar su sentimiento, al notar que [f. $5 \mathrm{v}$ ] se eligen unas circunstancias como las presentes para desviarse [la Santa Sede] de la senda acostumbrada en tales concesiones, no insistirá por ahora en que se amplíe el plazo de un año, concedido por Su Santidad; pero al mismo tiempo que se dan por el Gobierno español tantos y tan auténticos testimonios de estar animado de un espíritu de conciliación y avenencia, no puede menos de declarar de la manera más explícita que no consentirá bajo ningún motivo ni pretexto que el M.R. Arzobispo de Toledo ni otra cualquiera persona (por muy elevado que sea su carácter y distinguidas sus cualidades y [f. $6 r$ ] circunstancias) egerza (sic) una autoridad delegada por la $\mathrm{S}^{\text {ta. }}$ Sede en aquellas materias (como la de que ahora se trata), en que el Gobierno español tiene el derecho indisputable de designar la persona, en quien no habiendo motivo fundado de exclusión, haya de recaer la competente delegación, con arreglo a la práctica constante seguida en estos Reinos.

\footnotetext{
53 Véase nota 52 supra.

54 Urgía el nombramiento de Comisario de Sta. Cruzada al objeto de que no se paralizase la percepción y correcta administración del producto de la bula correspondiente de preceptiva adquisición por los fieles. Pero Roma, en lugar de nombrar al propuesto por el Gobierno (Mariano Liñán Morelló, canónigo de Valencia) designó al arzobispo de Toledo, cardenal Pedro de Inguanzo, y además no por diez años como era lo normativo sino por solo uno, aunque prorrogable si la Santa Sede lo estimaba conveniente. Sobre esta cuestión, véase Cárcel Ortí, V. 1975: 197-200.

55 Delegaciones éstas, como otras similares, a las que se oponía
} el Gobierno español.
S.M. se lisongea (sic) de que esta declaración, no menos franca que sincera, de cuales son sus principios y sentimientos en las graves materias que están pendientes en el día entre la $\mathrm{S}^{\text {ta. }}$ Sede y el Gobierno español, servirá para acelerar su terminación [f. $6 \mathrm{v}$ ] de un modo igualmente justo que decoroso para entrambas partes. Habiendo sido la voluntad de S.M., por no omitir medio alguno de acercarse a un fin tan importante, que al mismo tiempo que se dan las instrucciones convenientes al Encargado de Negocios en Roma, conformes al tenor y espíritu de esta Nota, tenga yo la honra de dirigirla a manos de V.E., cuyo ánimo conciliador y prudente discernimiento pueden ser de suma utilidad en las actuales circunstancias.

Aprovecho esta [f. 7r] ocasión para reiterar a V.E. las seguridades de mi alta consideración y aprecio.

Dios gu ${ }^{\text {e. }}$ A V.E. $\mathrm{m}^{\mathrm{s}}$ a a $^{\text {s. Palacio } 14}$ de Enero de 1835.

Excmo. Señor B.L.M. de V.E. su atento seg[ur]o servidor, FRANCISCO MARTÍNEZ DE LA ROSA.

\section{Sr. Arzobispo de Nicea."}

\section{BiBLIOGRAFÍA}

Andrés Gallego, J. y Pazos, Antón M. 1999. La Iglesia en la España contemporánea, I. 1800-1936. Madrid: Ediciones Encuentro.

Artola, M. 1973. La burguesía revolucionaria (1808-1869). Madrid: Alianza Ed.-Alfaguara.

Artola, M. 1975. Los orígenes de la España Contemporánea. 2a ed. Madrid: IEP, vol. I (2 vols.).

Artola, M. 1991. Partidos y programas políticos, 1808-1936. Madrid: Alianza Editorial, vol. I, (2 vols.).

Bécker, J. 1908. Relaciones diplomáticas entre España y la Santa Sede durante el siglo XIX. Madrid: Jaime Ratés.

Burdiel, I. 1987. La política de los notables. Moderados y avanzados durante el régimen del Estatuto Real. Valencia: Instituto "Alfons el Magnanin".

Cánovas Sánchez, F. 1982. El Partido Moderado. Madrid: CEC.

Cárcel Ortí, V. 1974. "Gregorio XVI y España". Archivum Historiae Pontificiae 12: 235-285.

Cárcel Ortí, V. 1975. Política eclesial de los Gobiernos liberales españoles (1830-1840). Pamplona: Univ. de Navarra: 143-318.

Cárcel Ortí, V. (ed.) 1982. Correspondencia diplomática de los Nuncios en España. Nunciatura de Amat. 1833-1840. Pamplona: EUNSA.

Castillo y Ayensa, J. del 1859. Historia crítica de las negociaciones con Roma desde la muerte de Fernando VII. Madrid: Tejado, vol. I (2 vols.).

Cuenca Toribio, J.M. 1965. Don Pedro de Inguanzo y Rivero (17641836), último primado del Antiguo Régimen. Pamplona: Univ. de Navarra.

Cuenca Toribio, J.M. 1967: “La desarticulación de la Iglesia española del Antiguo Régimen (1833-1840)". Hispania Sacra (CSIC) 20: 33-98.

Cuenca Toribio, J.M. 1971. La Iglesia española ante la Revolución liberal. Madrid: Ed. Rialp.

Cuenca Toribio, J.M. y Miranda García, S. 1998. El poder y sus hombres. ¿Por quienes hemos sido gobernados los españoles? (1705-1998). Madrid: Ed. Actas.

Decarretc, Á.Ma . 1885. Martínez de la Rosa. Madrid: Ateneo de Madrid.

Diario de Sesiones de las Cortes. Estamento de Procuradores. Legislatura de 1834-1835. Madrid. Imp. de J.A. García. 1867.

Fontana, J. 1977. La Revolución liberal. (Política y Hacienda -18331845-). Madrid: IEF.

Godart, L. 1962. Martínez de la Rosa. Ses oevres et sa vie. París: Plon, imp.

Gorricho Moreno, J. 1962. "El pretendiente Carlos V y el papa Gregorio XVI". Anthologica Annua 10: 731-741.

Gorricho Moreno, J. 1983. "Algunos documentos vaticanos referentes al pretendiente Carlos V (1834-1842)". Anthologica Annua 11: 339-365. 
Izaguirre Irureta, F. 1958. "Las relaciones diplomáticas de la Santa Sede con el Gobierno español durante la primera guerra carlista". Universidad (Zaragoza) 35: 569-593.

Jemolo, A.C. 1947. "I principii della guerra carlista e la Nunziatura di Madrid”. Ressegna Storica del Risorgimento 34, I-II: 6-14.

Jover, J.Ma. 1999. “Caracteres de la política exterior de España en el siglo XIX", en J.Ma. Jover, España en la política internacional. Siglos XIX y XX. Madrid: Marcial Pons -reimpresión de eds. precedentes111-172.

López-Cordón Cerezo, Mạ.V. 1983: “La política exterior” en J.Ma . Jover (dir.), La era isabelina y el Sexenio democrático (1834-1874), t. XXXIV de Historia de España. Menéndez Pidal. Madrid: EspasaCalpe: 821-899.

Marichal, C. 1980. La revolución liberal y los primeros partidos políticos en España: 1834-1844. Madrid: Ediciones Cátedra.

Martínez de la Rosa, F.: Obras. Edición y estudio preliminar de Carlos Seco Serrano. Madrid: Rivadeneyra, 1962 (BAE, ts. 148-155).

Moliner Prada, A. 1998. "Anticlericalismo y revolución liberal (18331874)" en E. La Parra López y M. Suárez Cortina (eds.): El anticlericalismo español contemporáneo. Madrid: Ed. Biblioteca Nueva: 69-126.

Morelli, E. 1966. La politica estera di Tommaso Bernetti, segretario di Stato di Gregorio XVI. Roma: Edizioni di Storia e Letteratura.

Moreno Alonso, M. 1979. Historiografía romántica española. Introducción a la Historia del siglo XIX. Sevilla: Univ. de Sevilla.

Nieto, A. 1996. Los primeros pasos del Estado constitucional. Historia administrativa de la Regencia de María Cristina. Barcelona: Ariel.

Nieva, J.Ma . de (ed.) 1835. Decretos de la Reina Nuestra Señora Doña Isabel II, dados en su Real nombre por su Augusta Madre la Reina Gobernadora, y Reales órdenes, resoluciones y reglamentos generales expedidos por las Secretarías del Despacho Universal desde 1 을 de enero hasta fin de diciembre de 1834. Madrid: Imprenta Real, t. XIX.

Pereira, J.C. 1983. Introducción al estudio de la política exterior de España (siglos XIX y XX). Madrid: Ed. Akal.

Pérez Alhama, J. 1967. La Iglesia y el Estado español. Estudio históricojurídico a través del Concordato de 1851. Madrid: IEP.

Pérez de la Blanca Sales, P. 2005. Martínez de la Rosa y sus tiempos. Prólogo de Juan C. Gay Armenteros. Barcelona: Ariel.

Rebello da Silva, L.A. 1864. Memoria sobre la vida política y literaria de D. Francisco Martínez de la Rosa. Madrid (1a ed.: Lisboa, 1863).
Renouvin, P. 1982. Le XIX siécle. I: De 1815 a 1871. L'Europe des nationalités à l'eveil de nouveaux mondes, t. V de Histoire des Relations Internationales. Madrid: Aguilar -1a ed. Francesa. París. 1954-.

Revuelta González, M. 1992. "El estallido anticlerical de 1834". xx Siglos, a. 3, 11: 136-141.

Revuelta González, M. 2010. La exclaustración, 2a ed., Madrid: Fundación Universitaria San Pablo CEU -1aㅡ ed.: Madrid, BAC, 1976-.

Sánchez, R. 2000. "La historia del siglo XIX desde la perspectiva moderada: reflexiones de Antonio Alcalá Galiano sobre España". Hispania (CSIC) LX-1: 289-314.

Sánchez, R. 2005. Alcalá Galiano y el liberalismo español. Prólogo de J.A. Martínez Martín. Madrid: CEPC.

Sarrailh, J. 1930. Un homme d'Êtat espagnol: Martínez de la Rosa (1787-1862). Bordeaux: Bibliotheque de l'École de Hautes Études Hispaniques.

Sosa, L. de 1930. Martínez de la Rosa, político y poeta. Madrid: Espasa-Calpe.

Suárez Verdaguer, F. 1958. La crisis política del Antiguo Régimen en España (1800-1840). 2a ed. Madrid: Rialp.

Suárez Verdaguer, F. 1963. "Génesis del Concordato de 1851", lus Canonicum, III, fasc. 1-2: 65-149.

Suárez Verdaguer, F. 2002. "El anticlericalismo español en el siglo XIX", en P. Aubert (ed.), Religión y sociedad en España (siglos XIX y XX). Madrid: Casa de Velázquez: 155-178.

Tomás Villarroya, J. 1968. El sistema político del Estatuto Real (18341836). Madrid: IEP.

Urquijo Goitia, J.R. 2001. Gobiernos y ministros españoles (18082000). Madrid: CSIC.

Varela Suanzes-Carpegna, J. 2005. El conde de Toreno. Biografía de un liberal (1786-1843). Prólogo de M. Artola. Madrid: Marcial Pons Ediciones.

Vilar, J.B. 1989. "Las relaciones internacionales de la España isabelina: precisiones conceptuales y anotaciones bibliográficas" en J.B. Vilar (ed.), Las Relaciones internacionales en la España contemporánea. Presentación de J.Mạ. Jover. Murcia-Madrid: Univ. de Murcia-Univ. Complutense 37-80.

Vilar, J.B. 2010. "España en la Europa de los nacionalismos: entre pequeña nación y potencia media (1834-1874)", en J.C. Pereira (coord.), La política exterior de España. De 1800 hasta hoy. Historia, condicionantes y escenarios. Barcelona: Ariel: 535-554. 